\title{
COVID-19 Pandemic and Yoga practice -New prescription for Stress Reduction?
}

\author{
Vini Vijayan, MD, FIDSA ${ }^{1}$, Niveditha Sukesh ${ }^{2}$, Devi Asokan MBBS ${ }^{3}$, Aiswarya Premkumar ${ }^{4}$ and Sukesh \\ Sukumaran, $\mathrm{MD}^{5}$
}

${ }^{1}$ Division of Infectious Diseases, Department of Pediatrics, Valley Children's Hospital, Madera CA, United States.

${ }^{2}$ Buchanan High School, Clovis, California, United States.

${ }^{3}$ Division of Pulmonology, Lisie Hospital, Kochi, Kerala, India.

${ }^{4}$ Government Medical College Paripally, Kollam, Kerala, India.

${ }^{5}$ Division of Rheumatology, Department of Pediatrics, Valley Children's Hospital, Madera CA, United States.

\begin{abstract}
The emergence of COVID 19 pandemic since December 31 2019, and isolation of novel SARS-CoV-2 changed the world. Since then, cases have spread all over the globe including 213 Countries/ territories. As the coronavirus spreads throughout the world, so has the ramifications of its spread impacted every aspect of our daily lives. While the physical, economic and social consequences of this pandemic have been enormous, its toll on the mental health and stress level of the general public is especially significant and should be addressed. Mandatory stay at home orders, social distancing measures, the closure of schools, parks, visitation in nursing homes, while necessary to contain the spread, may additionally lead to declining mental health. The latest statistics show that a whopping 264 million individuals worldwide suffer from clinical depression.

We propose the use of some simple Yoga practices to cope with this stressful situation and also to address the immune boosting effect of this practice. Proper practice of Yoga assists in mental clarity as well as emotional and physical control. It also helps with stress relief and increases one's awareness of the physical body rhythms. In this article we address simple Yoga and how to practice it with illustrations. We discuss the available literature regarding Yoga and its benefit in stress and immune-boosting.
\end{abstract}

\section{KEYWORDS}

COVID-19, Pandemic, Stress, Yoga, Immune Modulation.

Correspondins Author Information

Sukesh Sukumaran, MD

Medical Director, Pediatric Rheumatology, Division of Rheumatology, Valley Children’s Healthcare, Madera CA 93636 , Office 559 353 6450; Fax: 5593538373.

Received: August 04, 2020; Accepted: August 26, 2020; Published: September 02, 2020

Copyright: (C) 2020 ASRJS. This is an openaccess article distributed under the terms of the Creative Commons Attribution 4.0 International license.

Citation: Vini Vijayan, Niveditha Sukesh, Devi Asokan, Aiswarya Premkumar, Sukesh Sukumaran. COVID-19 Pandemic and Yoga practice -New prescription for Stress Reduction?. Med Clin Res Open Access. 2020;1(1):1-5. 


\section{Introduction}

The word Yoga came from the Sanskrit word "yuj" meaning to unite. Yoga is defined as the union of one with many and thus Yoga is described as the union of Athma, the consciousness in living body, with Paramathma, the super consciousness or super soul $[1,2]$.

Yoga is being practiced in ancient India for more than 10,000 years and was used as an ancient tool in Hindu culture for attaining and maintaining physical and psychological health. The consistent practice of Yoga helped to obtain the peace and happiness. Ancient yogic practice is considered as something which beyond the achievement of mere physical health. The description of yoga is seen in different religious textbooks as old as Vedas and Upanishads. The yoga practice also seen in many other religious text books including Buddhism, Jainism and Hinduism. The use of yoga as an adjuvant therapeutic intervention was started in late $19^{\text {th }}$ century.

However there is significant lack of evidence regarding the usefulness of yoga as an alternative or adjuvant in day to day practice. The available evidence seems to be inconsistent as many studies reporting positive effects of yoga intervention while other studies were inconclusive. In many instances, these inconsistencies resulted from difference between the yoga intervention, the frequency of intervention and association with breathing exercises versus independent yoga asana alone. This was affected by significant difference in study population including age and health status and underlying disease process.

In this article we summarize the current evidence on the clinical effect of yoga in immune system. The World Health Organization defines health as a complete wellbeing in terms of physical, mental and social and not merely the absence of the disease. The article is intended for health care providers across the board including Physicians, Nurse practitioners or physician assistants who would prefer to try alternative ways to help the patient population who is currently suffering from the COVID 19 pandemic.

The need for healthy immune system is integral in protecting against infections as well as malignancies. The immune system comprised of two branches- innate immune system and adaptive immune system. The innate immune system constitutes first line of defense against infections and hence it is very important in early recognition and triggering of the inflammatory response. The adaptive immune system is responsible for elimination of pathogens and helps in the generation of long-term immunological memory [3].

In the context of the Novel Corona virus (COVID 19) pandemic, we are evaluating the utility of Yoga practice to boost the immune system as well as to help with managing the stress.

Latent viral reactivation has been associated with stress as shown in many studies [4]. Viruses have the potential to cause both latent and lytic cycles of replication. Alternative signaling pathways that involves RAS/NF $\mathrm{k} \mathrm{B}$ are seems to be involved in reactivation of different viruses [5]. Stress has been associated with delay in wound healing as well as causing upper respiratory tract [6,7]. Yoga has shown to prevent autonomic changes and impairment of the cellular immune system $[8,9]$. Structured yoga practice has shown improvement in general health and immune parameters as well as quality of life in a pilot study in pediatric population reflected by HIV. Study showed statistically significant increase in CD4 cell count and improvement in CD4/CD8 ratio and improved psychomotor performance [6]. Iyengar yoga intervention has shown benefit in fatigue and circulating markers of inflammation in breast cancer survivors [10].

There is a significant growing body of knowledge the on structured practice of yoga has shown significant improvement in immunomodulation [11].

Natural Killer cell (NK cell) numbers are increased significantly after 3 to 6 months of structured yoga practice [12]. NK cells helps in eliminating damaged cells and cancer cells. Interferon (IFN) Gamma is also secreted from NK cells which helps and pro inflammatory function by activating macrophages and endothelial cells [13]. It has been shown that interleukin-4 levels increased and interferon gamma levels decreased during stress [14]. The patients who practiced structured Hatha Yoga has been found to lower level of IFN-Gamma [15]. Studies also supported reduction in IL6 and TNF -alpha levels in a short-term yoga based lifestyle program [16].

Structured her the yoga also shown to decrease IL-6, TNF alpha, IL-1 beta 3 production and hence reduce inflammation [17]. Yoga practice has shown to down regulate pro inflammatory genes and potentially down regulating TNF-R11, IL-1 rA and CRP $[18,19]$.

\section{Discussion}

The impact of COVID 19 pandemic and its implications on stress level in general public and health care providers are enormous. The gentle practice of the following yoga practice is not only helpful for the patients and families but also for doctors, nurse Practitioners, nurses and other health care works both in the university setting and also in small practices. The daily yoga practice will help not only the providers but also the patients as well in these difficult times of COVID 19 pandemic.

Yoga practice had shown significant immune modulating effect. It seems to be helpful in different disease processes including HIV infections. Yoga has shown to down regulate inflammatory mediation. It also shown to influence autonomic nervous system, endocrine system and hypothalamic pituitary axis. It also shown to improve psychological health in patient population [20-23].

Immune system activation takes time and need structured Yoga practice. There are different yoga practices to help with immune system activation. The common types of Yoga include Iyengar Yoga or Hatha Yoga and Ashtanga or Vinyasa yoga. Proper practice of Iyengar Yoga or Hatha Yoga helps to align and calming your mind, body and spirit. In Iyengar Yoga helps to lengthen and strengthen 
the muscles and through holding poses for a period of time. This practice of Yoga has shown significant improvement in balancing, flexibility and strength.

However with Ashtanga or Vinyasa Yoga helps to build strength. This practice helps to improve strength of the muscles and help in flexibility. Other less popular forms of Yoga include Bikram Yoga and Kundalini Yoga.

The idea that yoga is just flexing and extending ones muscle and just helps to only improve flexibility is being propagated. The ultimate goal of yoga practice should be to help the way you perceive one's life and the lives around you.

We suggest yoga practice to overcome the stressful situation of COVID 19 pandemic and also to improve one's immune health includes the following. The yoga pose or Asana can be divided into Standing Asana, Sitting Asana and Reclining Asana. We suggest regular practice of the following asana

Common Standing Asana includes the following -

Figure 1: Tadasana (Mountain Pose

Figure 2: Pranamasana (Prayers Pose)

Figure 3: Hastha Udhanasana (Raised Arms Pose)

Figure 4: Vrikshasana (Tree Pose).

Common sitting Asana include the following:

Figure 5: Padmasana (Lotus Pose on Left) and Ardha padmasana (Half lotus pose on Right)

Figure 6: Sukhasana (Easy Pose)

Figure 7: Balasana (Child Pose)

Common reclining Asana include the following:

Figure 8: Bhujangasana (Cobra Pose)

Figure 9: Urdhva Mukha Svanasana (Upward Facing Dog),

Figure 10: Apanasana (Knee- Chest Pose).

Figure 11: Savasana (Corpse Pose)

Please refer to the following figures.

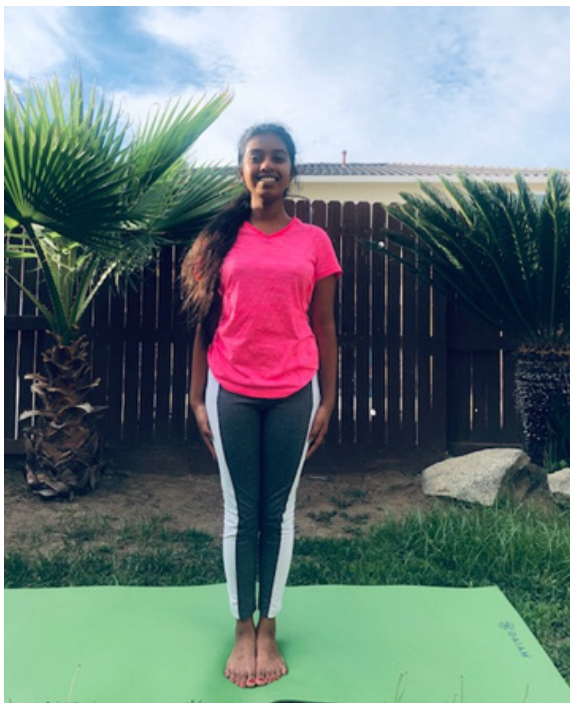

Figure 1: Tadasana or Mountain pose.
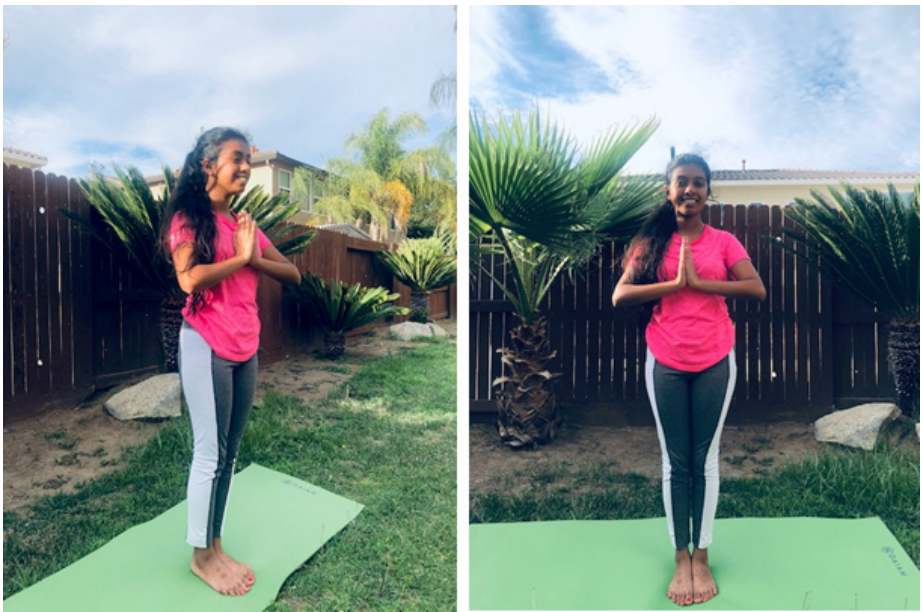

Figure 2: Pranamasana or Prayer Pose.
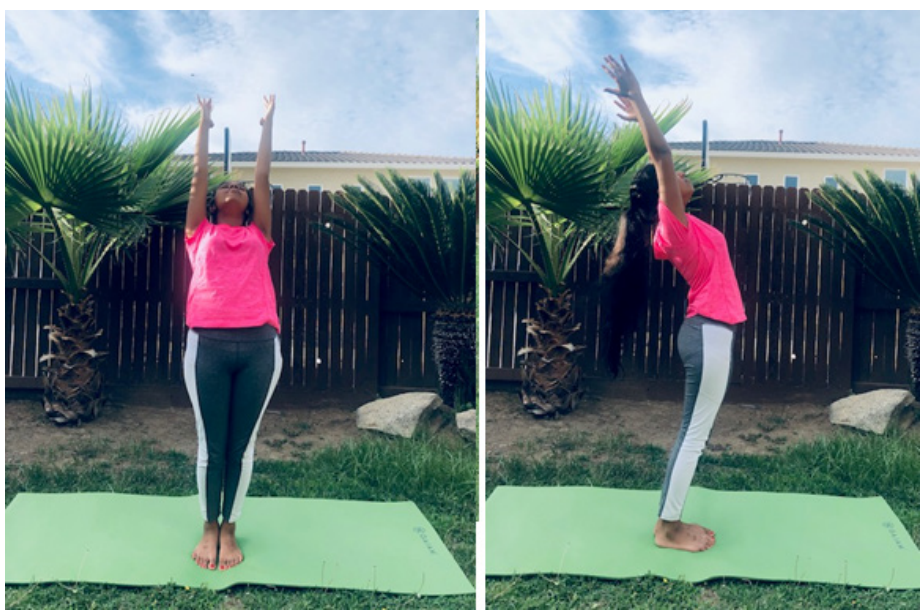

Figure 3: Hastha Udhanasana or Straight Hand Raising Pose.
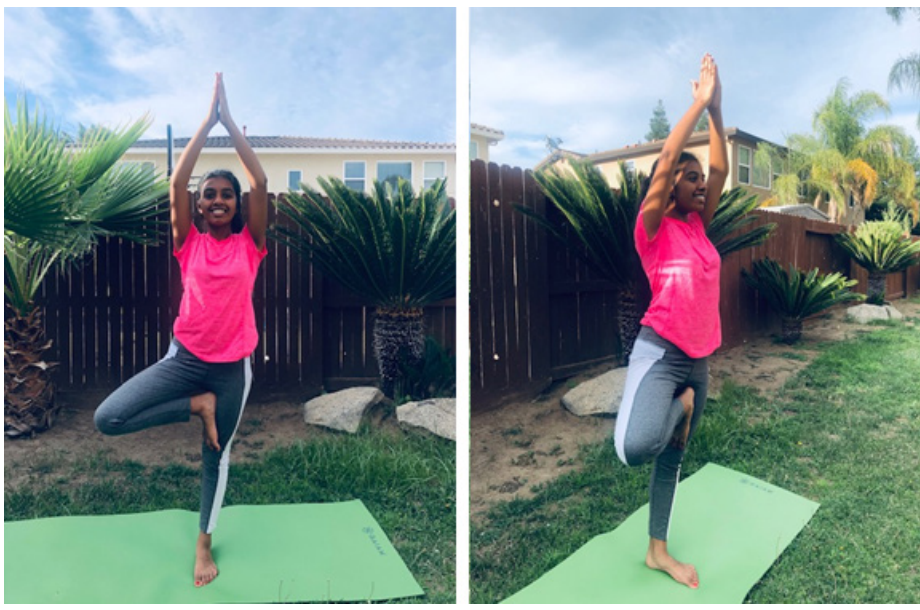

Figure 4: Vrikshasana or Tree Pose. 

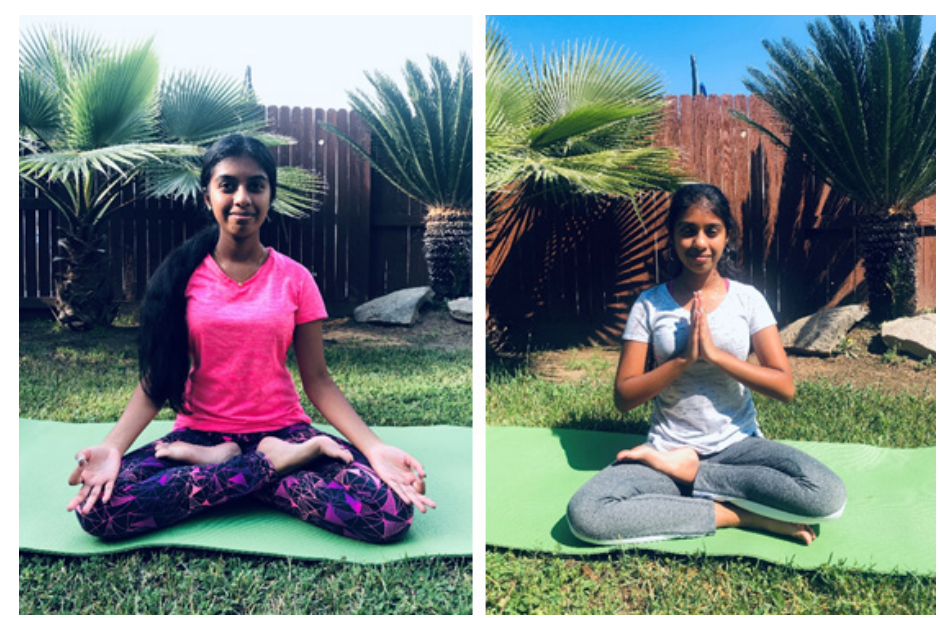

Figure 5: Padmasana or Lotus pose and Ardha Padmasana or Half Lotus pose.

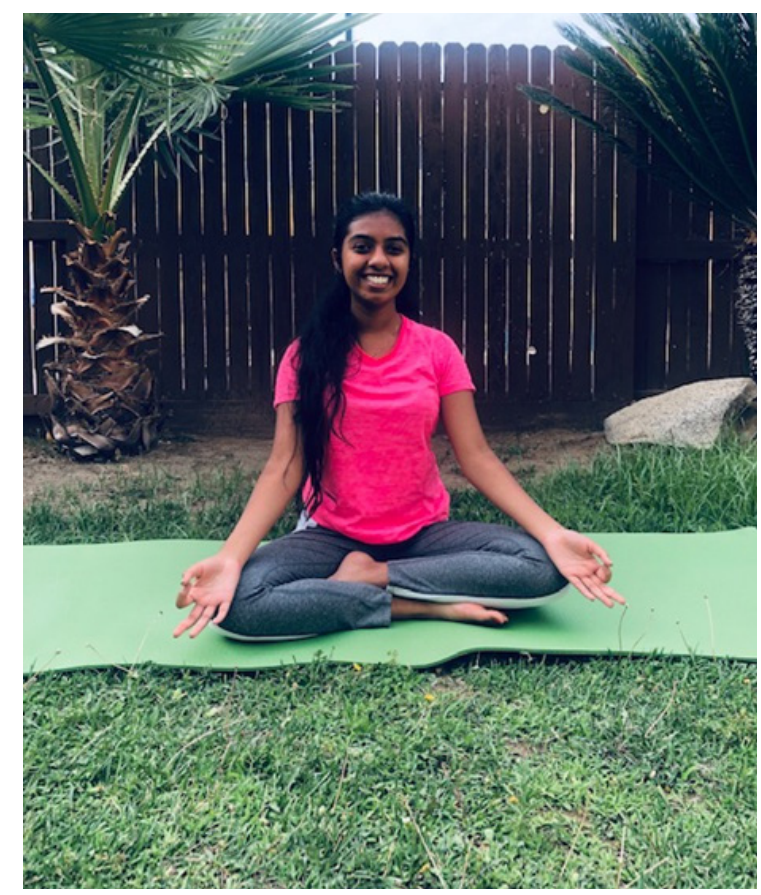

Figure 6: Sukhasana or Easy Pose.

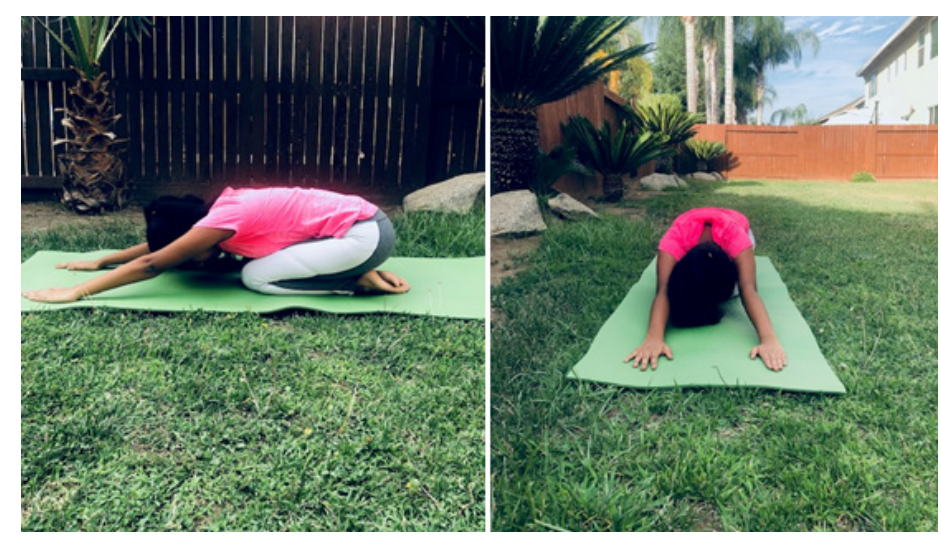

Figure 7: Balasana or Child Pose.
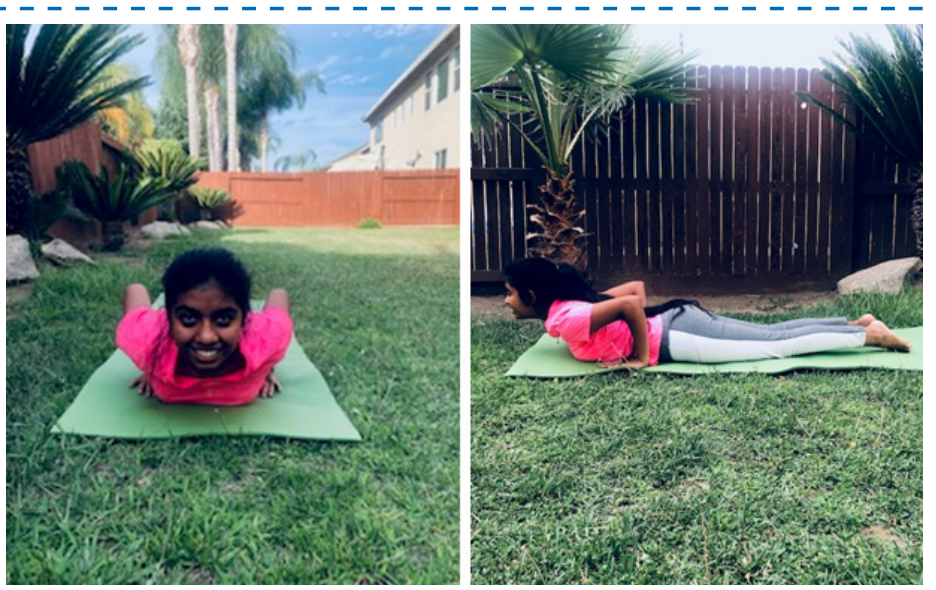

Figure 8: Bhujangasana or Cobra pose.
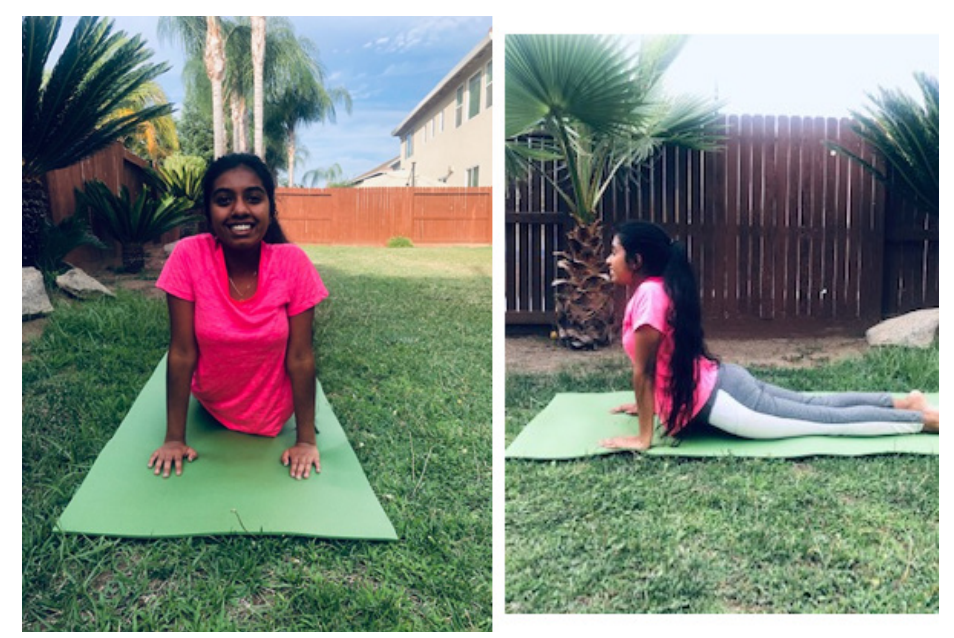

Figure 9: Urdhva Mukha Shvanasana or Upward facing Dog.

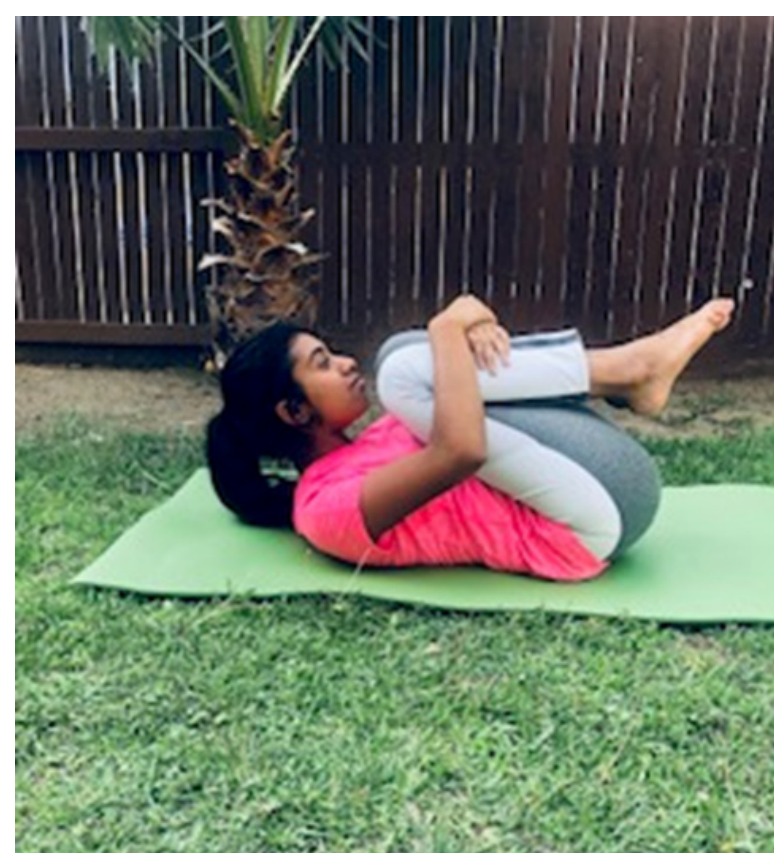

Figure 10: Apanasana or Knee Chest Pose. 


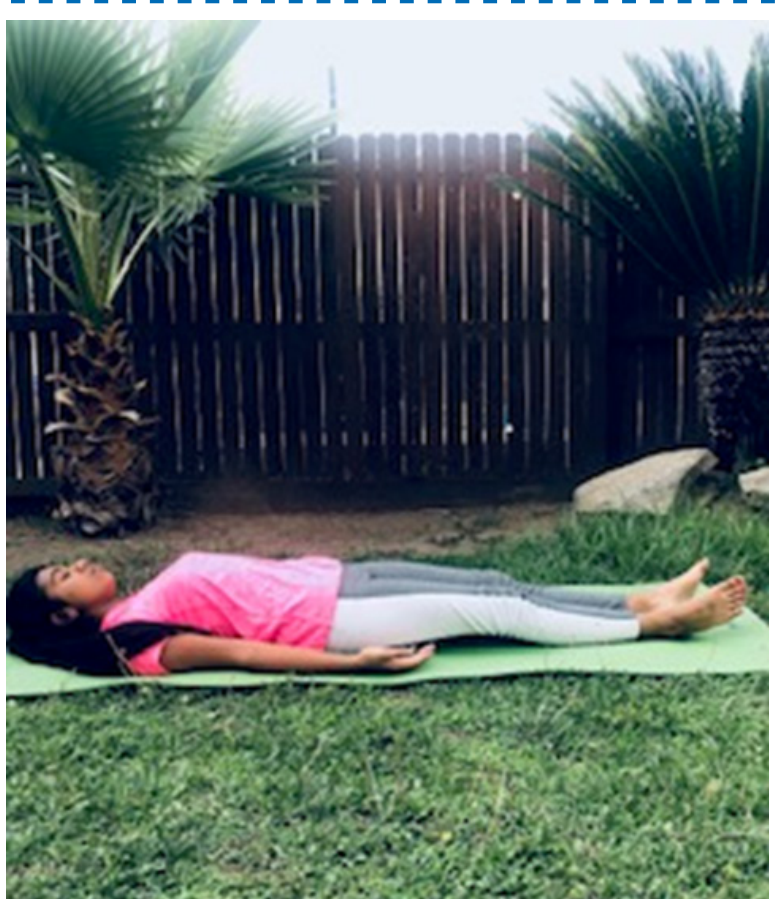

Figure 11: Savasana or Corpse Pose.

\section{References}

1. Light on Yoga - NY- Schocken Books; 1966. BKS Iyengar

2. Yoga in schools: A systematic review of literature. International Journal of yoga therapy. 2012: (22): 101-109.

3. Textbook of pediatric rheumatology Cassidy and Patty 6th edition-2011.

4. Stress, loneliness, and changes in herpesvirus latency.Glaser R, Kiecolt-Glaser JK, Speicher CE, Holliday JE J Behav Med. 1985 Sep; 8(3):249-60.

5. Virus reactivation: Have panoramic view in human infections. Shaw, M A; Future virology: 2011 April: 6(4): 451-463.

6. Cohen S. Psychological stress, immunity and upper respiratory infections. Curr Dir Psychol Sci. 1996; 5:86-90.

7. Mucosal wound healing is impaired by examination stress. Marucha PT, Kiecolt-Glaser JK, Favagehi M Psychosom Med. 1998 May-Jun; 60(3):362-5.

8. Emotions, Immunity and Disease; A speculative theoretical integration. Solomon GF; Moss RH; Arch Gen Psychiatry. 1964 Dec; 11():657-74.

9. Effective integrated yoga practices on immune response in examination stress-preliminary study. A Gopal, J Bhattacharjee- Int J Yoga 2011

10. Yoga reduces inflammatory signaling in fatigued breast cancer survivors: A randomized control trial. Steve. WC; Psycho Neuro Endocrinology. 2014 May: 43: 20-29.

11. Molecular Signature of the Immune Response to Yoga Therapy in Stress-related Chronic Disease Conditions, Venkatesh HN, Ravish H, Wilma DS, Srinivas H. International Journal of yoga 2020

12. Oxidative stress and pathogenesis of neurodegenerative disorders. Mosley RL, Int Rev Neurobiology.2007: 82: 297-325

13. Effect of rhythmic breathing (Sudarshana Kriya and Pranayama) on immune functions. Kochupillai V, Ann NY Academic Science 2005: 1056: 242-52.

14. Psychological stress may induce increased humoral and decreased cellular immunity.Paik IH; Behavioral Medicine 2004: 26(3): 139-141.

15. Effective integrated yoga practices on immune response in examination stress-preliminary study. A Gopal, J Bhattacharjee- Int J Yoga 2011

16. Efficacy of a short term yoga based lifestyle intervention in reducing stress and inflammation: Preliminary results. J Altern Compl Med-2012; 18:662-7.

17. Yoga has impact on inflammation, mood, fatigue and breast cancer survivors: A randomized control trial. Malrkey, WB et al. Journal of clinical oncology. 2014; 32:1040-9

18. A systematic review of gene expression changes induced by meditation and related practices- Brazil IA. Front Immunolo. 2017;8:670

19. Effect of yoga training on inflammatory cytokines and C-reactive protein in employees of small scale industriesBhogal RS et al; Journal of education and health promotion; 2017;6:76

20. Effect of yoga on anti-retroviral adherence post incarceration and HIV positive individuals-Journal of healthcare 2020 January 26(1);83-94

21. Levels of immune cells in transcendental meditation practitioners. Roldan A; International Journal of yoga 2014 July;7(2); 147-51

22. Virus reactivation: Have panoramic view in human infections. Shaw, M A; Future virology: 2011 April: 6(4): 451-463.

23. Psychological stress may induce increased humoral and decreased cellular immunity. Paik IH; behavioral medicine 2004: 26(3): 139-141. 